\title{
Microscopical characterization of the salivary glands of the carnivorous cephalaspidean Philinopsis depicta (Mollusca, Opisthobranchia)
}

\author{
A. Lobo-da-Cunha**** I. Ferreira* and G. Calado*** \\ * Institute of Biomedical Sciences Abel Salazar (ICBAS), Porto University, Portugal \\ ** Centre of Marine and Environmental Research (CIMAR), Porto, Portugal \\ *** Lusophone University of Humanities and Technologies, Lisbon and Institute for Marine \\ Research (IMAR), FCT/UNL, Caparica, Portugal \\ alcunha@icbas.up.pt
}

Cephalaspideans are a group of opisthobranch gastropods comprising carnivorous and herbivorous species [1], allowing an investigation of the relationship between these diets and the morphofunctional features of the salivary glands.In this study, the salivary glands of the carnivorous cephalaspidean Philinopsis depicta were observed by light microscopy using semithin sections and by transmission electron microscopy. A central duct runs along the length of these thin ribbon-shaped glands dividing them in two halves, each formed by a single row of tubules perpendicularly attached to the central duct. The simple epithelium of the central duct and lateral tubes contains ciliated cells and two types of secretory cells, named granular cells and cells with apical vacuole (Fig. 1). A very thin outer layer of connective tissue covers the epithelium (Fig. 1). The ciliated cells are numerous but very thin, forming small clusters between secretory cells. The nucleus, several mitochondria and a few lysosomes are located in the apical region were the cells are wider. A very thin cytoplasmic stalk reaches the base of the epithelium and contains bundles of filaments in addition to some mitochondria. Additionally, ciliated cells possess large amounts of glycogen granules. The granular cells are packed with large electron-dense secretory granules (Fig. 2). In the cytoplasm around these granules several cisternae of rough endoplasmic reticulum can be seen and Golgi stacks with flatted cisternae are also present. In some of these cells, the granules were almost all fused together forming a large mass of electrondense secretion. The secretory granules are strongly positive to PAS reaction and to the tetrazonium reaction for protein detection, being stained by alcian blue due to the presence of acid polysaccharides. The other type of secretory cell is mainly characterized by the presence of a large vacuole in the apical region, containing secretion. These cells have high amounts of flattened cisternae of rough endoplasmic reticulum and several Golgi stacks formed by flat cisternae containing spots of electrondense material. Many vesicles with peripherally located electron-dense material are also abundant (Fig. 3), and seem to fuse to form the large apical vacuole. At advanced stages of maturation, the cytoplasm below the apical vacuole condenses and become highly electron-dense. The secretory material of these cells is PAS positive and contains proteins, but is weakly stained by alcian blue. Previous studies about herbivorous opisthobranchs have revealed different cell types in the salivary glands $[2,3]$. Thus, the available data point to significant differences between the salivary glands of carnivorous and herbivorous cephalaspidean opisthobranchs, with an intensification of protein secretion in carnivorous species and preponderance of mucus components in the saliva of herbivorous.

\section{References}

[1] H. Wägele, A. Klussmann-Kolb. Front. Zool. 2 (2005) 3.

[2] A. Lobo-da-Cunha. Acta Zool., 82 (2001) 201.

[3] A. Lobo-da-Cunha, G. Calado. Inv. Biol., 127 (2008) 33. 


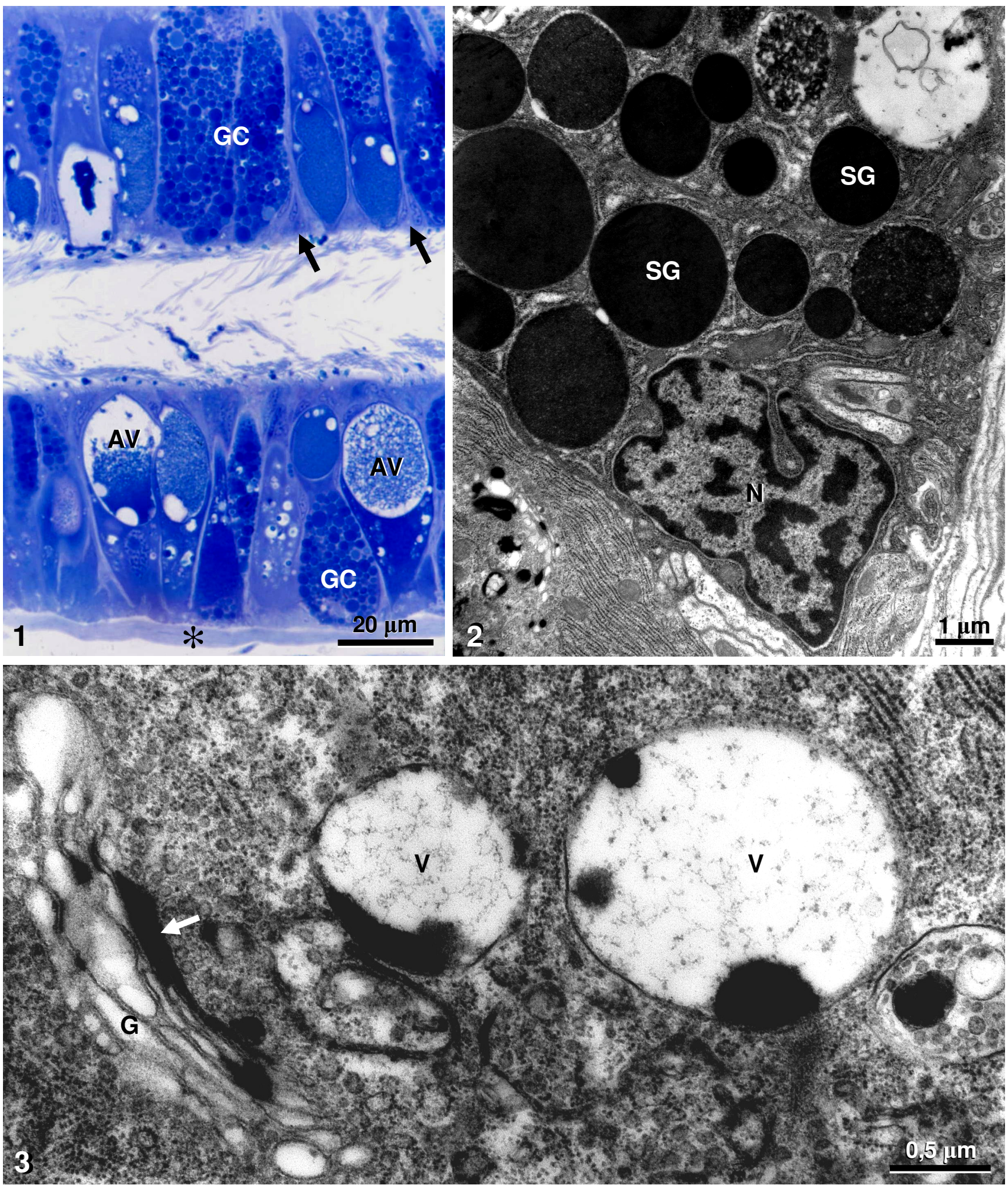

Fig. 1 Semi-thin section of a salivary gland, showing ciliated cells (arrows), granular cells (GC), cells with apical vacuole (AV) and the other layer of connective tissue (asterisk). Fig. 2 The granular cells contain a large number of electron-dense secretion granules (SG) and a basal nucleus (N). Fig. 3 Golgi stack $(\mathrm{G})$ with electron-dense material in the trans face cistern (arrow) and vesicles with peripheral spots of electron-dense material (V) in a cell with apical vacuole. 